\title{
Evaluation of Gold, Silver and Silver-Gold (Bimetallic) Nanoparticles as Radiosensitizers for Radiation Therapy in Cancer Treatment
}

\author{
B. Shameer Ahmed ${ }^{1}$, Anil G. Rao ${ }^{2}$, B M Sankarshan ${ }^{3}$, C.S. Vicas ${ }^{1}$, K. Namratha ${ }^{1}$, T.K. Umesh ${ }^{3}$, \\ R. Somashekar ${ }^{1, *}$, K. Byrappa ${ }^{1}$ \\ ${ }^{1}$ Centre for Materials Science and Technology, Vijnana Bhavan, University of Mysore, Mysuru,- 570006, Karnataka, India \\ ${ }^{2}$ Department of Radiology and Radiological Science, Medical University of South Carolina, 96 Jonathan Lucas St, MSC 323, Charleston, \\ SC 29425-3230, USA \\ ${ }^{3}$ Department of Studies in Physics, University of Mysore, Manasagangotri, Mysuru- 570006, Karnataka, India \\ *Corresponding Author: rs@physics.uni-mysore.ac.in
}

Copyright $(2016$ by authors, all rights reserved. Authors agree that this article remains permanently open access under the terms of the Creative Commons Attribution License 4.0 International License

\begin{abstract}
One of the most recognized and widely used treatment modality in cancer is radiation therapy which depends on the radiosensitivity of tumour tissue. Over the past few years there has been lot of interest in the use of formulations to enhance radiotherapeutic effects, especially using metallic (mainly gold) based nanoparticles. Our goal here is to fabricate nanoparticles (NPs) that can be delivered to tumor tissue to increase its radiosensitivity. This would increase efficiency of radiation absorption by the tumor tissue and reduce radiation doses delivered during radiotherapy. This could potentially decrease radiation exposure related side effects to patients. We have achieved this by synthesizing nanoparticles of high $\mathrm{Z}$ elements such as gold, silver and a more efficient bimetallic silver-gold size ranging from $3 \mathrm{~nm}$ to $72 \mathrm{~nm}$ using chemical reduction and hydrothermal method. The synthesized metallic nanoparticles were characterised using Ultraviolet (UV)-Visible Spectroscopy, Fluorescence spectroscopy and Dynamic Light Scattering. The metallic nanoparticles showed radiosensitizing activity in colloidal form by absorbing radiations when irradiated by ${ }^{60} \mathrm{Co}$ source which emits two gamma rays of energy $1173 \mathrm{keV}$ and $1332 \mathrm{keV}$. Based on our results, we are of the opinion that such radio-sensitizing agent if injected into the tumour tissue would increase radiation absorption and enhance treatment effect with lower therapeutic radiation dosage.
\end{abstract}

Keywords Radiosensitizers, Silver-Gold (Bimetallic) Nanoparticles, Gamma Radiation, Gold Nanoparticles, High-Z Metal Nanoparticles, Enhanced Radiation Therapy

\section{Introduction}

Every year 10.9 million people worldwide are diagnosed with cancer, and there are 6.7 million reported deaths from the disease [1]. There are continuous efforts across the globe to come up with more efficient and safe treatment modalities for cancer. Often radiation therapy is used in cancer treatment [2]. The success of radiation therapy depends on the radiosensitivity or radioresistance of tumour tissue in consideration with surrounding normal tissue. Radiation resistance of tumour tissue is a key challenge in oncology [3]. Radiosensitizers are agents that enhance the positive effects of radiation therapy. Over the past few years there has been lot of interest in the use of formulations to enhance radiotherapeutic effects, especially using metallic (mainly gold) based nanoparticles [4]. Nanoparticles can be combined with radiation therapy where metallic particles can selectively absorb and/or scatter the high energy gamma radiations. This allows for better targeting of cellular components within the tumour tissues allowing for more localized and enhanced damage. NPs also provide enriched interaction cross-section with the photons from X-rays or high energy radiations and gamma irradiations $[5,6]$.

Delivering a therapeutic dose of radiation to tumour tissues while preserving normal surrounding tissues is still a great task in radiation therapy. Acquired radiation resistance during treatment is one of the major causes of radiation therapy failure and subsequent tumour relapse. Three major approaches for the improvement of efficacy of radiation therapy and minimize associated risks/complications have been put forward (I) enhancing radiosensitization of tumour tissue (II) reversing of radiation resistance in tumour tissue and (III) enhancing radioresistance of the healthy tissue [7].

Radiosensitization is done by strategically using high- $Z$ NPs. These NPs can intensify the production of secondary electrons or Auger electrons and reactive oxygen species (ROS) that in turn enhance radiation therapy effects [8]. The most studied NPs are gold-based NPs (GNPs) that were 
widely described in particular by Hainfeld et al. [9]. Literature shows that of late titanium oxide nanotubes, lanthanide-based NPs or cadmium selenide quantum dots are being used [10-13]. Other studies have shown use of silver-based NPs which take advantage of its excellent surface enhanced Raman scattering and broad-spectrum antimicrobial activities [14]. However, silver NPs cause dose dependent toxicity and induce oxidative stress and DNA damage in triple negative breast cancer [15]. Radiosensitization by gold NPs (GNPs) are dependent upon six factors that include intracellular localization, size, concentration, radiation dose, cell type and modified surface of these nanoparticles [16].

Chitrani et al demonstrated that GNPs around $50 \pm 5 \mathrm{~nm}$ diameter had the highest radio enhancement factor (REF) $(1.43$ at $220 \mathrm{kVp})$ compared with GNPs of 14 and $74 \mathrm{~nm}$ (1.20 and 1.26, respectively) [17]. The highest cellular uptake of GNPs was found to be at 50nm particle size [18]. Hence, we have considered the size of NPs $(50 \mathrm{~nm} \pm 5 \mathrm{~nm})$ to be one of important factors in our work while synthesizing bimetallic silver-gold, silver and gold NPs.

Our hypothesis is that bimetallic silver-gold NPs will be the best radiosensitizing agent as they may have better absorption coefficient and non-toxic. Gamma radiation transmission experiment was conducted to evaluate the radio sensitizations of NPs.

For this purpose, a narrow beam transmission experiment was carried out using ${ }^{60} \mathrm{Co}$ source with silver, gold and silver-gold nanoparticle solutions of various size distribution as targets by employing a high resolution hyperpure germanium detector. The variation of photon mass attenuation coefficient for each sample so obtained was correlated with the radiosensitizing capacity of NPs. Possible conclusions are drawn based on the present study.

\section{Materials and Methods}

\subsection{Reagents}

Chloroauric acid $\left(\mathrm{HAuCl}_{4}\right.$, Aldrich chemicals, Silver Nitrate $\left(\mathrm{AgNO}_{3}\right.$, Sigma chemical company), Tri-Sodium Citrate Dihydrate (Himedia), ultrapure water (purity up to 18.2 $\mathrm{M} \Omega \mathrm{cm}^{-1}$ Elga Option Q7).

\subsubsection{Synthesis of Nanoparticles.}

Colloidal NPs such as gold, silver and silver-gold (bimetallic) were synthesized by chemical reduction and hydrothermal method.

Precursors, reducing agent and concentration for synthesis of various nanoparticles are given in table 1.

Gold nanopolyhedra were grown using the seeded growth method. Au NPs are most commonly synthesized through the reduction of chloroauric acid $\left(\mathrm{HAuCl}_{4}\right)$ by sodium citrate resulting in an aqueous Au NPs colloid [19, 20]. Au NPs size (often measured in terms of diameter) can be modified by adjusting the chloroauric acid to sodium citrate ratio. Similarly Ag NPs are synthesized by reduction of Silver Nitrate $\left(\mathrm{AgNO}_{3}\right)$ by sodium citrate resulting in an aqueous Silver nanoparticles colloid [21].

\subsubsection{Chemical reduction}

The nanoparticles were synthesized in different batches. This was done by placing G1 sample i.e., $25 \mathrm{ml}$ of $1 \mathrm{mM}$ $\mathrm{HAuCl}_{4}$ solution in a round bottom flask. Round bottom flask was kept in a bowl of glycerine and heated indirectly. A motorized stir bar was placed in the solution and set to a spin rate of $400 \mathrm{rpm}$ and temperature was set $300^{\circ} \mathrm{C}$. The gold solution was heated until solution was boiling. To achieve a homogenous size of the gold nanoparticles solution, $1 \mathrm{ml}$ of $40 \mathrm{mM}$ sodium citrate solution was quickly added to the batch during continuous stirring. A colour shift from yellow to red was seen as the gold solution was reduced and the nanoparticles were synthesized. The solution was left to boil for another 10 minutes before the heating mantle was turned off. The size of gold nanoparticles generated depends on the concentration of $\mathrm{HAuCl}_{4}$, the amount of sodium citrate added and the duration of heat supplied. Also G3 was prepared in same way.

Similarly for silver nanoparticles precursor $25 \mathrm{ml}$ of $1 \mathrm{mM}$ $\mathrm{AgNO}_{3}$ was used. By using chemical reduction, samples S1, S2, SG1 and SG3 were synthesized by altering the precursors and maintaining amount of the reducing agent to be $1 \mathrm{ml}$ of trisodium citrate at same concentration $40 \mathrm{mM}$, except in S2 sample where $5 \mathrm{ml}$ of reducing agent was added in order to alter the size of nanoparticles. S3 was prepared just by mixing ingredients in a vial and kept undisturbed for 1 day.

Table 1. Precursors and reducing agents used in synthesis of nanoparticles

\begin{tabular}{|c|c|c|}
\hline Sample & Precursor & Reducing agent \\
\hline G1 gold NPs & $25 \mathrm{ml}$ of $1 \mathrm{mM} \mathrm{HAuCl}_{4}$ & $1 \mathrm{ml}$ of $40 \mathrm{mM}$ trisodium citrate \\
\hline G2 gold NPs & $25 \mathrm{ml}$ of $1 \mathrm{mM} \mathrm{HAuCl}_{4}$ & $1 \mathrm{ml}$ of $40 \mathrm{mM}$ trisodium citrate \\
\hline G3 gold NPs & $25 \mathrm{ml}$ of $1 \mathrm{mM} \mathrm{HAuCl}_{4}$ & $1 \mathrm{ml}$ of $40 \mathrm{mM}$ trisodium citrate \\
\hline S1 silver NPs & $25 \mathrm{ml}$ of $1 \mathrm{mM} \mathrm{AgNO}$ & $1 \mathrm{ml}$ of $40 \mathrm{mM}$ trisodium citrate \\
\hline S2 silver NPs & $25 \mathrm{ml}$ of $1 \mathrm{mM} \mathrm{AgNO}_{3}$ & $5 \mathrm{ml}$ of $40 \mathrm{mM}$ trisodium citrate \\
\hline S3 silver NPs, & $25 \mathrm{ml}$ of $1 \mathrm{mM} \mathrm{AgNO}$ & $1 \mathrm{ml}$ of $40 \mathrm{mM}$ trisodium citrate \\
\hline SG1 silver -gold (bimetallic) NPs & $12 \mathrm{ml}$ of $\mathrm{AgNO}_{3}, 12 \mathrm{ml}$ of $\mathrm{HAuCl}_{4} \mathrm{Wt} \% 1: 1$ & $1 \mathrm{ml}$ of $40 \mathrm{mM}$ trisodium citrate \\
\hline SG2 silver -gold (bimetallic) NPs & $12 \mathrm{ml}$ of $1 \mathrm{mM} \mathrm{AgNO} 3,12 \mathrm{ml}$ of $1 \mathrm{mM} \mathrm{HAuCl}_{4}$ & $1 \mathrm{ml}$ of $40 \mathrm{mM}$ trisodium citrate \\
\hline SG3 silver -gold (bimetallic) NPs & $12 \mathrm{ml}$ of $1 \mathrm{mM} \mathrm{AgNO}{ }_{3}, 12 \mathrm{ml}$ of $1 \mathrm{mM} \mathrm{HAuCl}_{4}$ & $1 \mathrm{ml}$ of $40 \mathrm{mM}$ trisodium citrate \\
\hline
\end{tabular}




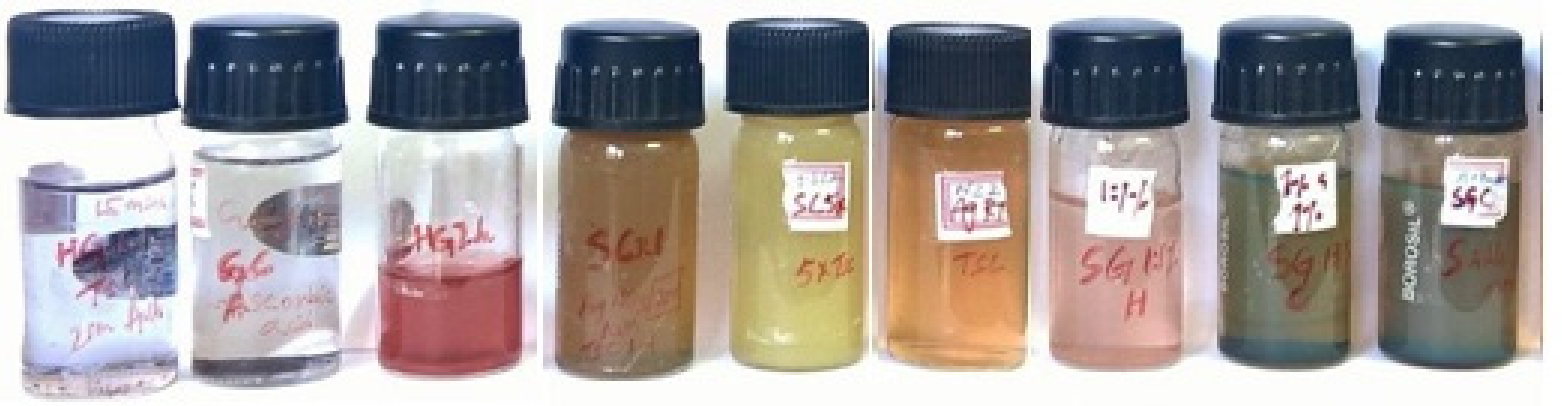

Figure 1. Synthesized nanoparticles from S1 to SG3 (gold, silver, silver-gold \{bimetallic\})

\subsubsection{Hydrothermal Synthesis}

For the hydrothermal synthesis of gold nanoparticles, $25 \mathrm{ml} 1 \mathrm{mM} \mathrm{HAuCl}_{4}$, and $1 \mathrm{ml}$ of $40 \mathrm{mM}$ trisodium citrate were added to a glass vial. Final mixture was then transferred to the Teflon liner $\left(\mathrm{V}_{\text {fill }}=26 \mathrm{ml}\right)$, which was later placed inside a general-purpose autoclave. The autoclaves were provided with Teflon liners of $50 \mathrm{ml}$ capacity. Then each assembled autoclave was kept in an oven with a temperature programmer-controller. The temperature was programmed and kept at $180^{\circ} \mathrm{C}$ for $1 \mathrm{hr}$ and autogenous pressure maintained. After the experimental run, autoclaves were cooled to room temperature. The resultant product in the Teflon liner was then transferred to clean glass vials. The sample SG2 was prepared at same temperature and methodology. The sample $\mathrm{G} 2$ was prepared at $180^{\circ} \mathrm{C}$ for 2 hours in the oven.

$0.9 \%$ Saline was used as an analogue of biological medium in a previous experiment by V. Apanasevich et al (2014) [22]. In our experiment we avoided using $0.9 \%$ of saline as an analogue because every material contributes to absorption of gamma rays during transmission experiment or total attenuation of gamma radiation experiment. Also addition of electrolyte or salts causes agglomeration and change in dynamics of nanoparticles in the colloidal solution which has been shown in previous experiments [23, 24]. The biological activity of nanoparticles depends on many physico-chemical factors and is regulated by virtue of stability. A reduction in stability leads to aggregation and consequently total or partial loss of nanoscale properties [25].

Synthesised particles demonstrated colours varying from red for smaller particles to purple for larger particles (Figure 1). The gold NP solution with particle size less than $30 \mathrm{~nm}$ was red whereas the larger size NP solutions were blue. The silver nanoparticles showed yellowish brown and silvergold bimetallic nanoparticles developed a dark-violet brownish colour.

\subsection{Characterization of Nanoparticles}

\subsubsection{Dynamic Light Scattering (DLS)}

Nanotrac analyzers from Microtrac were used to determine the size of nanoparticles in the prepared colloidal solution. The average mean diameter of the nanoparticles in colloidal solution as determined by dynamic light scattering measurements (Figure 2, 3 and 4) showed different size distributions of particles in the solution from S1 to SG3 with peaks of $4 \mathrm{~nm}$ to $73 \mathrm{~nm}$. Since particles are of ellipsoid in nature, they are characterised by two parameters namely major axis (diameter) and minor axis (width). Along with the average mean diameter and width of nanoparticles other important data have emerged out during DLS characterisation such as Zeta potential, Mobility, Charge and Polarity as shown in table 2 . All the particles are less than $100 \mathrm{~nm}$ range and above $3 \mathrm{~nm}$. Zeta potential of nanoparticles showed up to upper limit of device capacity $-200 \mathrm{mV}$. The samples will be termed according to the constituents of nanoparticles formed and size associated with it.

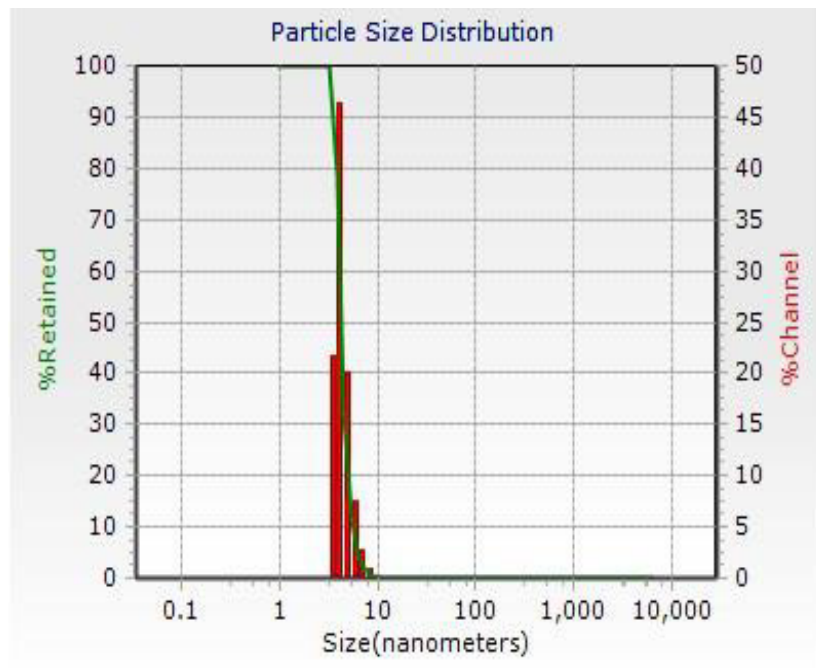

Figure 2(a). Dynamic light scattering distribution of $4.2 \mathrm{~nm}$ gold nanoparticles. 


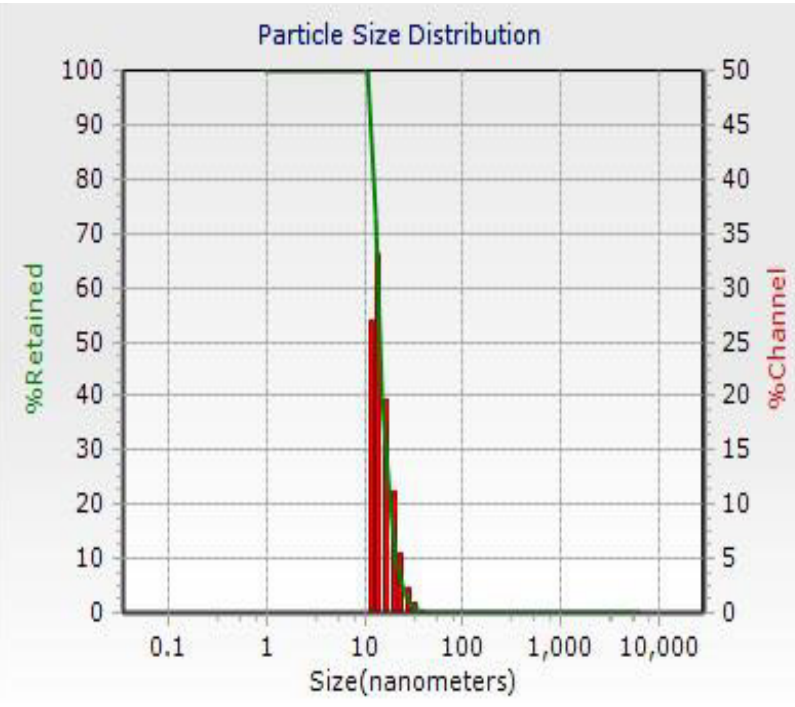

Figure 2(b). Dynamic light scattering distribution of $14.3 \mathrm{~nm}$ gold nanoparticles.

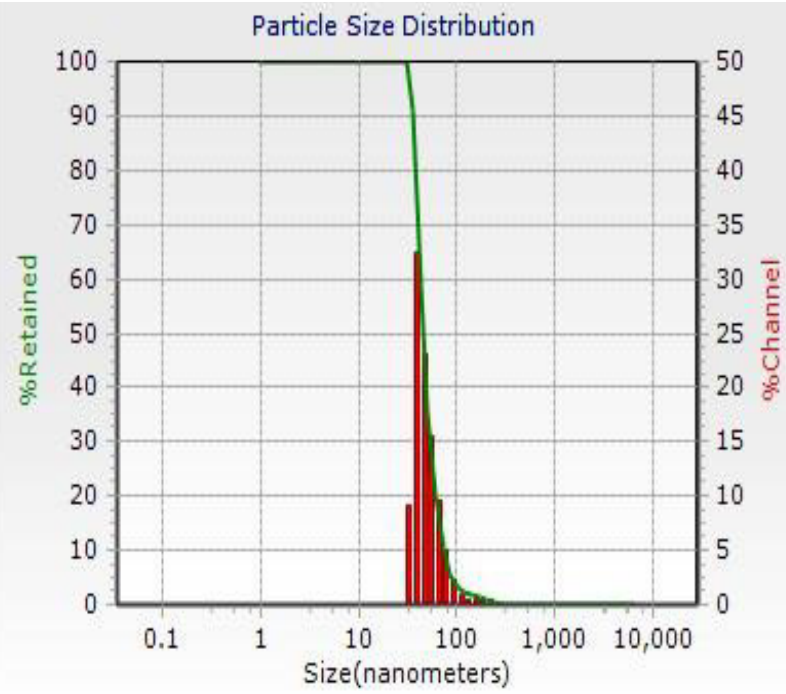

Figure 2 (c). Dynamic light scattering distribution of $45.5 \mathrm{~nm}$ gold nanoparticles.

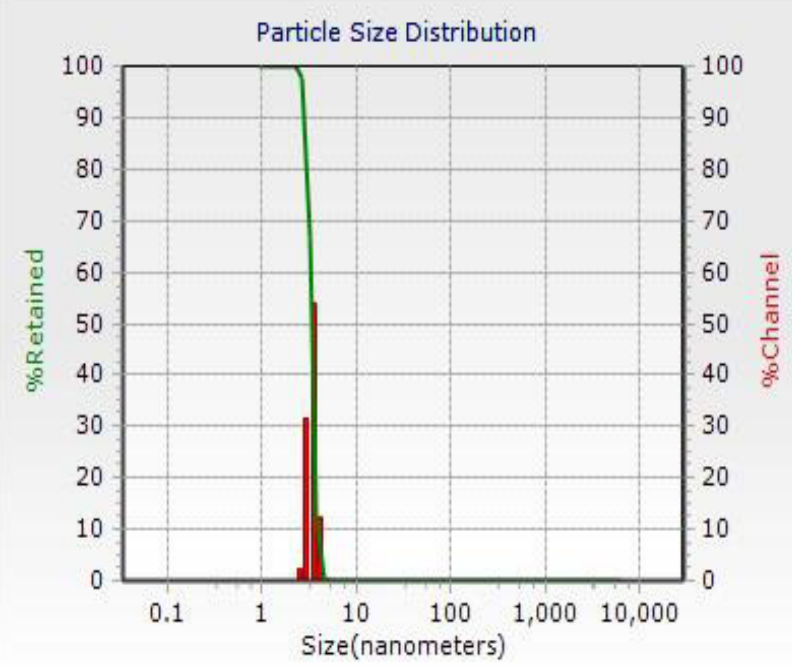

Figure 3(a). Dynamic light scattering distribution of $3.36 \mathrm{~nm}$ silver nanoparticles.

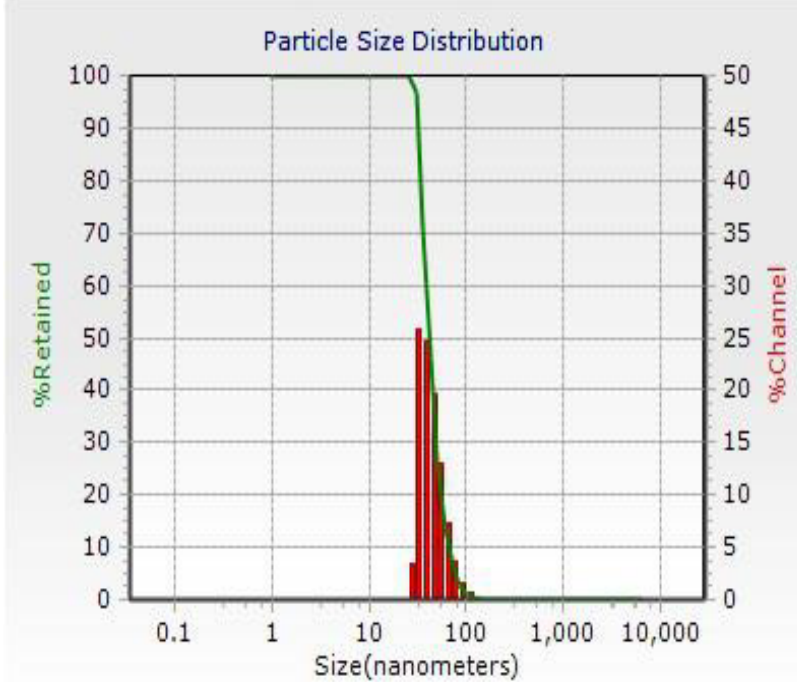

Figure 3(b). Dynamic light scattering distribution of $41.7 \mathrm{~nm}$ silver nanoparticles.

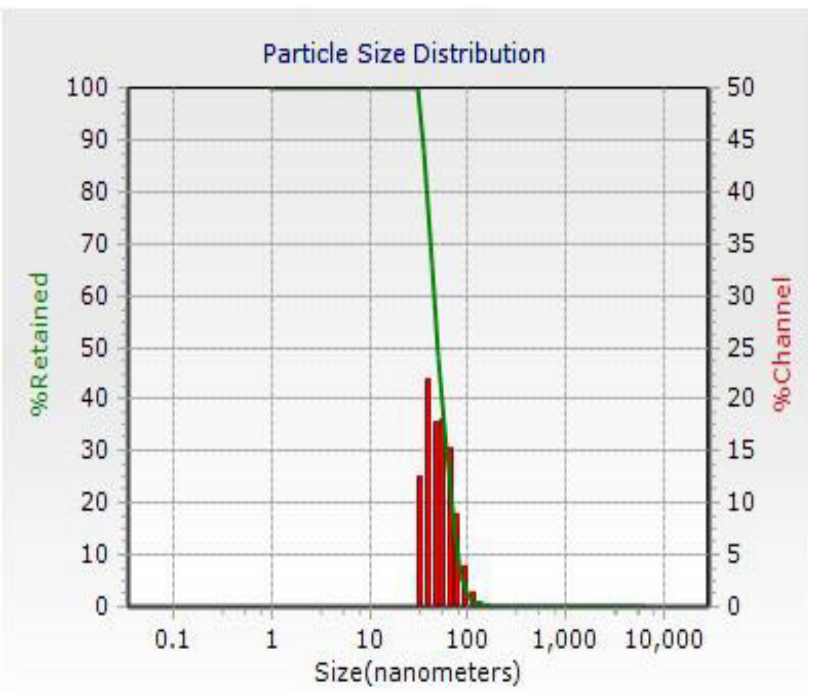

Figure 3(c). Dynamic light scattering distribution of $50 \mathrm{~nm}$ silver nanoparticles.

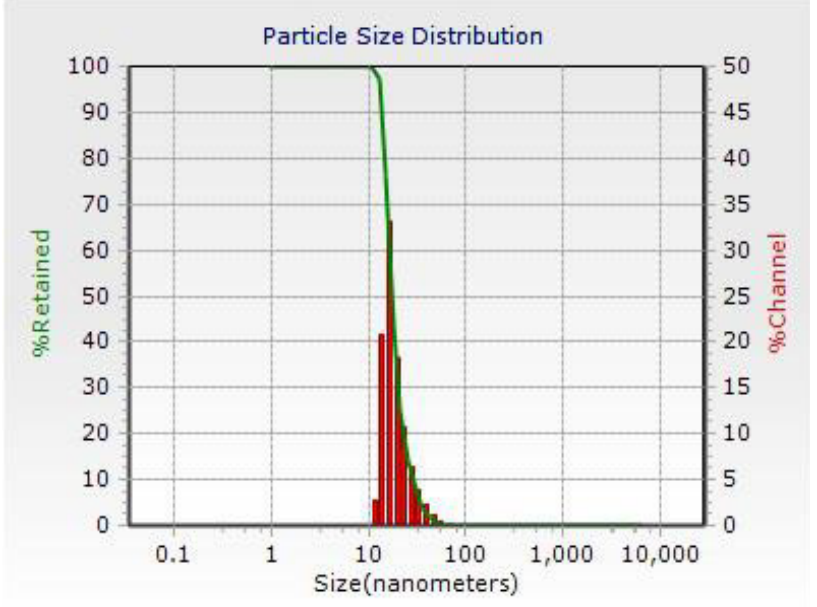

Figure 4(a). Dynamic light scattering distribution of $17.4 \mathrm{~nm}$ silver-gold (bimetallic) nanoparticles. 


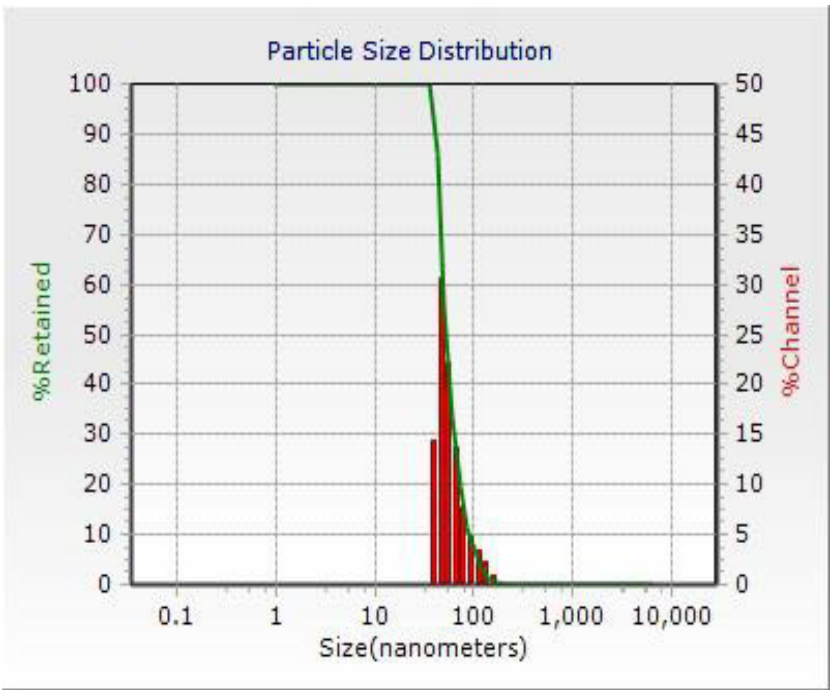

Figure 4(b). Dynamic light scattering distribution of $52.9 \mathrm{~nm}$ silver-gold (bimetallic) nanoparticles.

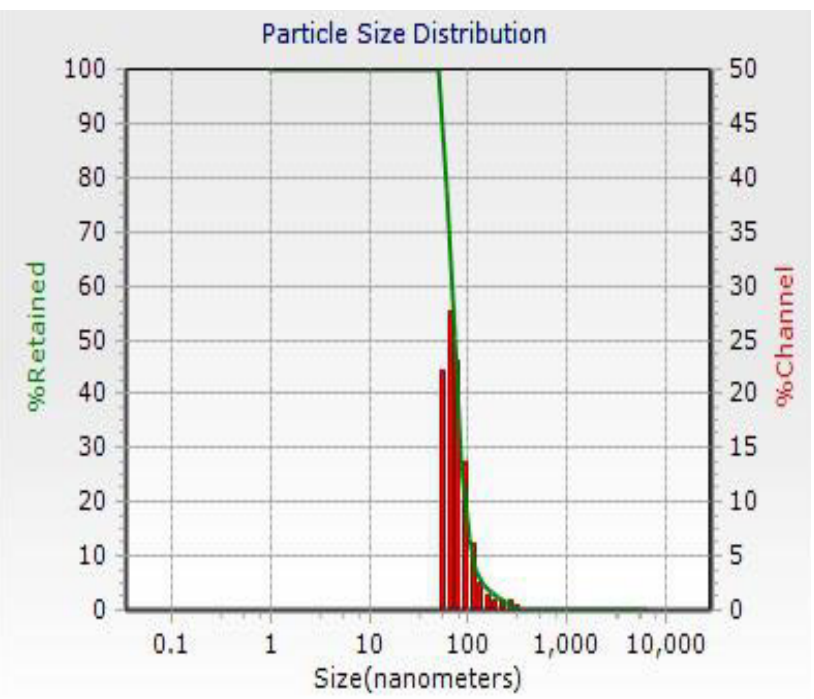

Figure 4(c). Dynamic light scattering distribution of $72.4 \mathrm{~nm}$ silver-gold (bimetallic) nanoparticles.

Table 2. Dynamic Light Scattering Data

\begin{tabular}{|c|c|c|c|c|c|c|}
\hline Sample & $\begin{array}{c}\text { Size } \\
\text { Diameter }(\mathrm{nm})\end{array}$ & Width & Zeta Potential & Mobility & Charge & Polarity \\
\hline G1 & 4.21 & 1.39 & $-16.8 \mathrm{mV}$ & $-1.31 \mathrm{u} / \mathrm{s} / \mathrm{V} / \mathrm{cm}$ & $-0.00054 \mathrm{fC}$ & Negative \\
\hline G2 & 14.35 & 7.01 & $-32.2 \mathrm{mV}$ & $-2.51 \mathrm{u} / \mathrm{s} / \mathrm{V} / \mathrm{cm}$ & $-0.00549 \mathrm{fC}$ & Negative \\
\hline G3 & 45.5 & 27.14 & $-200.0 \mathrm{mV}$ & $-15.63 \mathrm{u} / \mathrm{s} / \mathrm{V} / \mathrm{cm}$ & $-0.20923 \mathrm{fC}$ & Negative \\
\hline S1 & 3.36 & 0.79 & $-156.0 \mathrm{mV}$ & $-12.19 \mathrm{u} / \mathrm{s} / \mathrm{V} / \mathrm{cm}$ & $-0.00367 \mathrm{fC}$ & Negative \\
\hline S2 & 41.7 & 24.96 & $-200.0 \mathrm{mV}$ & $-15.63 \mathrm{u} / \mathrm{s} / \mathrm{V} / \mathrm{cm}$ & $-0.07315 \mathrm{fC}$ & Negative \\
\hline S3 & 50 & 33.9 & $-200.0 \mathrm{mV}$ & $-15.63 \mathrm{u} / \mathrm{s} / \mathrm{V} / \mathrm{cm}$ & $-0.08898 \mathrm{fC}$ & Negative \\
\hline SG1 & 17.4 & 10.2 & $-0.1 \mathrm{mV}$ & $-0.01 \mathrm{u} / \mathrm{s} / \mathrm{V} / \mathrm{cm}$ & $-0.00002 \mathrm{fC}$ & Negative \\
\hline SG2 & 52.9 & 33.7 & $-200.0 \mathrm{mV}$ & $-15.63 \mathrm{u} / \mathrm{s} / \mathrm{V} / \mathrm{cm}$ & $-1.42024 \mathrm{fC}$ & Negative \\
\hline SG3 & 72.4 & 39.4 & $200.0 \mathrm{mV}$ & $15.63 \mathrm{u} / \mathrm{s} / \mathrm{V} / \mathrm{cm}$ & $2.890 \mathrm{fC}$ & Positive \\
\hline
\end{tabular}

\subsubsection{Ultraviolet-visible (UV-VIS) spectroscopy}

Thermo Scientific Varioskan Flash Spectral Scanning Multimode Reader was used to carry out UV-Visible spectroscopy. It had plate types 6 - 384 well plates reading capacity, light source being Xenon flash lamp and wavelength range $200-1000$ $\mathrm{nm}$ and bandwidth of $5 \mathrm{~nm}$.

The absorbance maxima for gold, silver and gold-silver NPs were determined by UV-Vis spectrophotometer. The spectra are as shown in figure 5 (a-c). The absorbance maxima for gold NPs were found to be at 515, 527 and $517 \mathrm{~nm}$ which indicates that the gold nanoparticles are present based on the surface plasmon resonance. The absorbance maximum peaks of silver NPs were found to be at 418,415 and $456 \mathrm{~nm}$ which indicates that the silver nanoparticles were present based on the surface plasmon resonance. Absence of secondary peak in these spectra indicated that the nanoparticles were spherical in shape. Also surface plasmon absorption bandwidth is a maximum of $418 \mathrm{~nm}$ indicating the presence of spherical or roughly spherical. 


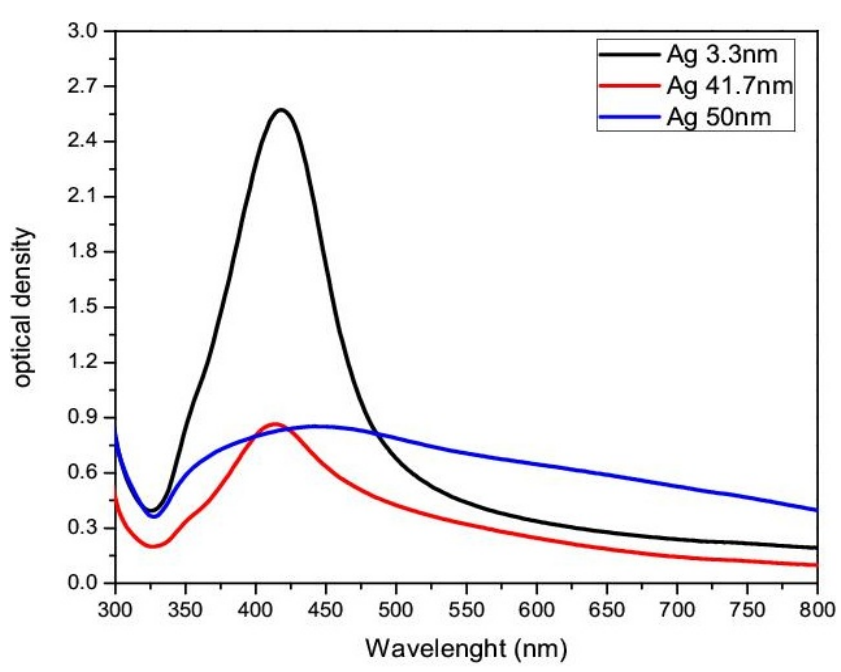

Figure 5(a). UV-Vis Spectrum of silver NPs

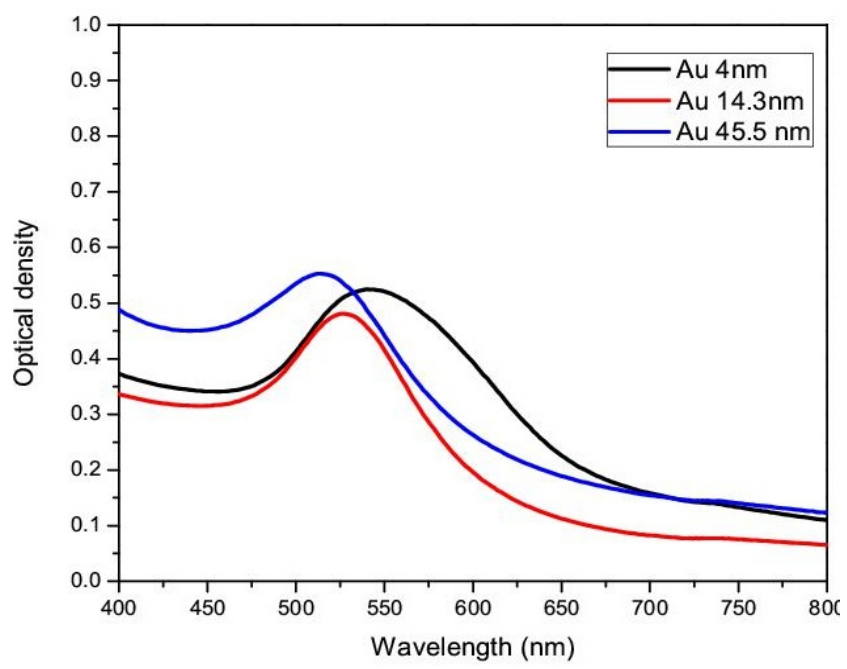

Figure 5(b). UV-Vis Spectrum of gold NPs

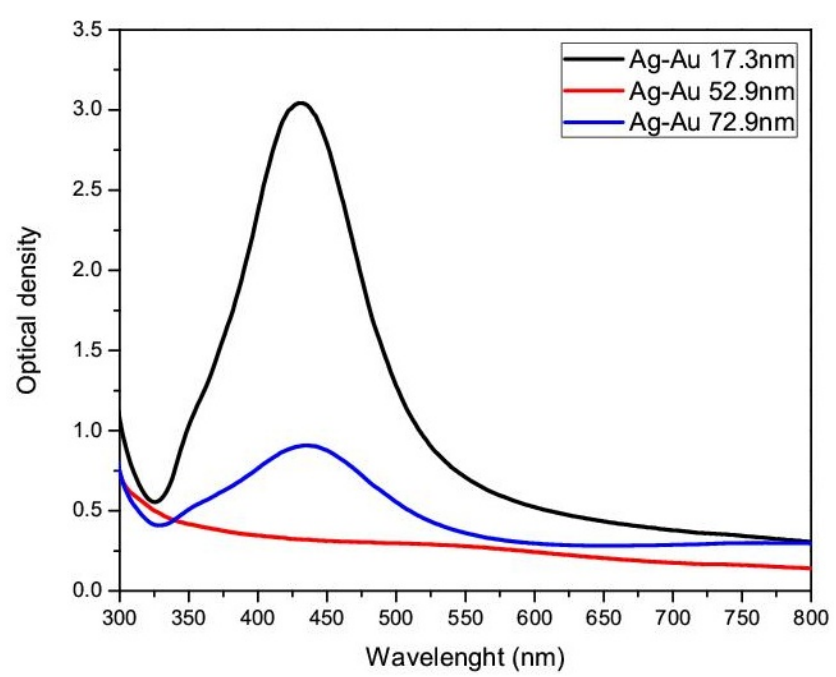

Figure 5(c). UV-Vis Spectrum of silver-gold (bimetallic) NPs

\subsubsection{Fluorescence Spectroscopy}

Thermo Scientific Varioskan Flash Spectral Scanning Multimode Reader was used for Fluorescence spectroscopy.
It had plate type $6-1536$ well plates reading capacity, light source Xenon flash lamp, excitation wavelength range 200 $1000 \mathrm{~nm}$, emission wavelength range $270-840 \mathrm{~nm}$, excitation/emission bandwidth $5 \mathrm{~nm}$ and $12 \mathrm{~nm} / 12 \mathrm{~nm}$.

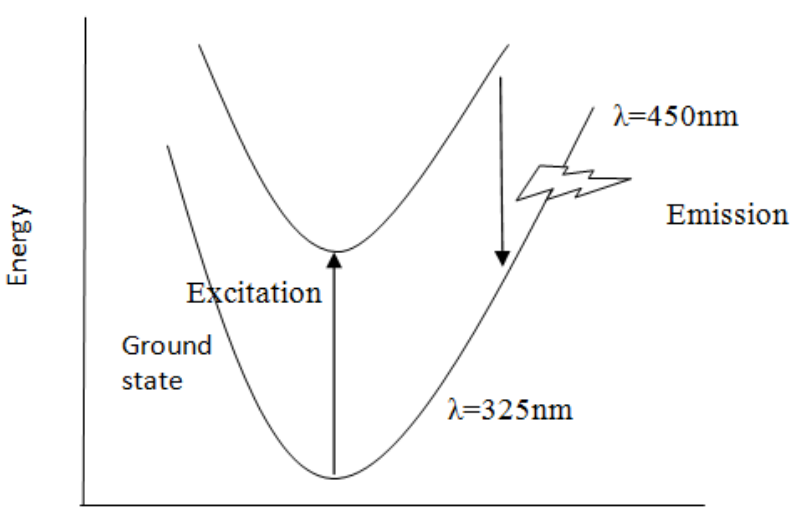

Distance (nm)

Figure 6. Energy v/s distance for nanoparticles

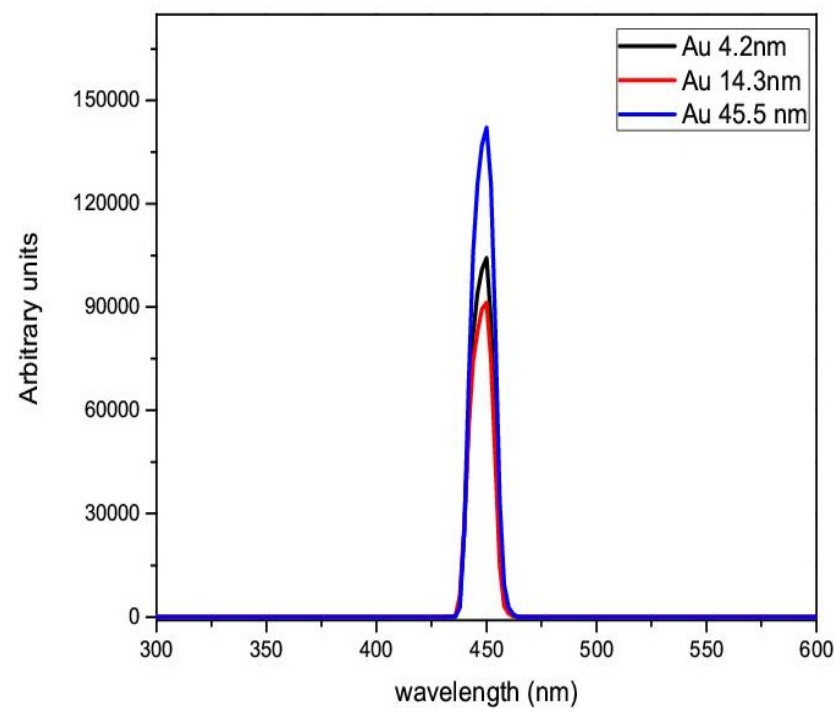

Figure 7(a). Fluorescence Spectrum of gold nanoparticles.

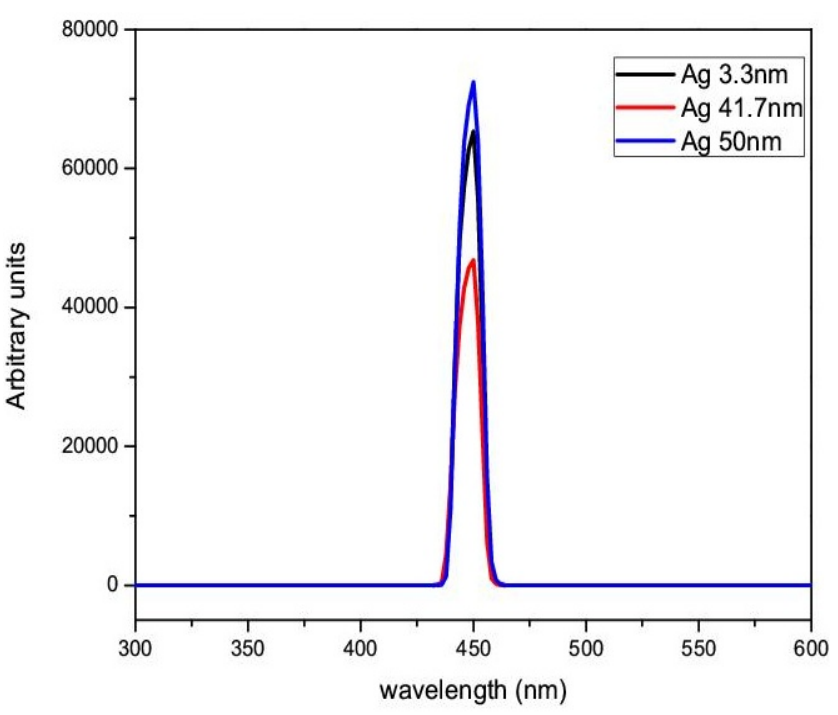

Figure 7(b). Fluorescence Spectrum of silver nanoparticles 


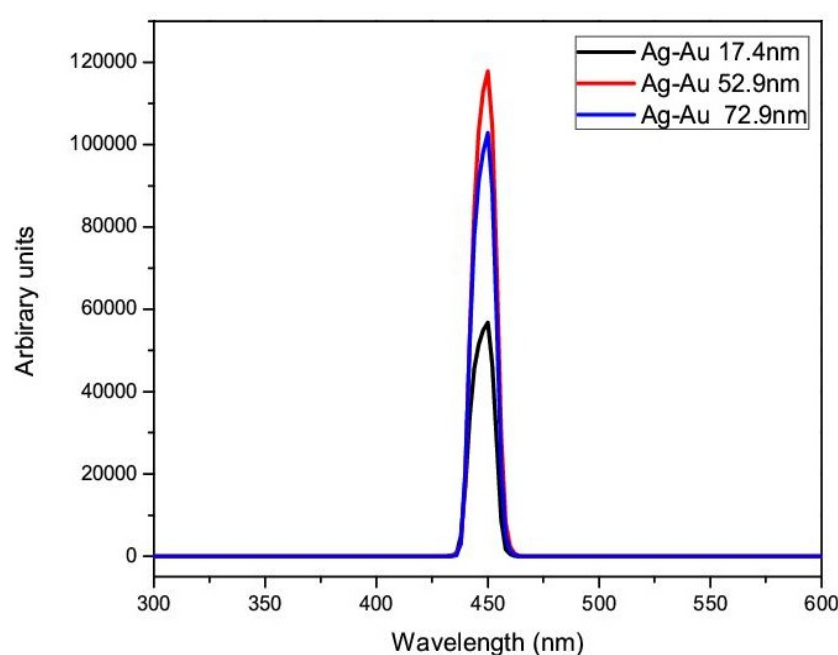

Figure 7(c). Fluorescence Spectrum of silver-gold (bimetallic) nanoparticles.

In this study, all nine samples were shown to possess fluorescence properties though at different degrees of intensity in addition to emission peak variance. The excitation of the samples at $325 \mathrm{~nm}$ resulted in the emission spectra as shown in Figure 6 with the emission peak maxima identified. The nanoparticles of gold, silver and silver gold bimetallic exhibited a single high intensity peak at $450 \mathrm{~nm}$ while there was little variation with regard to intensity comparison shown in figure $7(\mathrm{a}-\mathrm{c})$.

Liu et al reported similar results with very small gold nanoparticles $(5.1 \mathrm{~nm})$ stabilized with Bovine serum albumin (BSA) excited at $320 \mathrm{~nm}$ exhibiting an emission peak at 404 $\mathrm{nm}$ [26]. The presence of a single high intensity fluorescence peak for the samples after irradiation at $325 \mathrm{~nm}$ indicates that it is useful for bio-labelling applications as potential alternatives to organic fluorophores.

\subsection{Experimental Determination of Mass Attenuation Coefficient of Nanoparticles}

The photon mass attenuation coefficient was determined by a transmission experiment. The transmission experiment was performed in a setup similar to the one used in an earlier study [27]. The ${ }^{60} \mathrm{Co}$ source used in this study had a source strength of $132 \mathrm{kBq}$ and was procured from the Bhabha Atomic Research Centre, Mumbai, India. Gamma rays of energy $1173 \mathrm{keV}$ and $1332 \mathrm{keV}$ emitted by the ${ }^{60} \mathrm{Co}$ source were made to fall on the target. The transmitted intensities were detected using an EG \& G ORTEC model 23210 (USA) Gamma-x high purity germanium detector. The signal from the detector was suitably amplified and the spectrum was recorded in a personal computer based multichannel analyzer supplied by M/S Nucleonix Corporation Ltd, Hyderabad, India.

The nanoparticles under investigation were confined in cylindrical plastic containers. The samples were weighed in an electrical balance correct to the third decimal place. The weighings were repeated to obtain concordant values of the mass. The mean of this set of concordant values was taken to be the mass of the sample. The inner diameter of each container was determined separately with the help of a travelling microscope by the usual method. Based on the mean value of mass and inner diameter, the mass per unit area $(\rho t)$ of each sample was determined.

In the transmission experiment, spectra were recorded by placing the container with and without sample alternately in the path of the beam. The attenuation of the photon beam by the material of the empty container was negligible. The counting time was so chosen that at least $10^{4}-10^{5}$ counts were recorded under the photo peak.

\section{Results and Discussion}

Gold NPs of size 4.21, 14.35 and $45.5 \mathrm{~nm}$ were synthesized and width being 1.39, 7.01, $27.14 \mathrm{~nm}$ respectively. Silver NPs of size 3.36, 41.7 and 50nm were synthesized and width being 0.79, 24.96, $33.9 \mathrm{~nm}$ respectively. Silver-gold NPs of size 17.4, 52.9 and $72.4 \mathrm{~nm}$ were synthesized and width being 10.2, 33.7, $39.4 \mathrm{~nm}$ respectively.

The highest zeta potential and highest mobility in each group was found for 45.5nm Au NPs, 41.7 and 50nm Ag NPs as well as 52.9 and $72.4 \mathrm{~nm} \mathrm{Au-Ag} \mathrm{bimetallic} \mathrm{NPs}$ suggestive of a colloidal formation which could remain stable for a longer time than the NPs of other sizes respectively in each group.

UV-visible spectroscopy indicating a shift from $527 \mathrm{~nm}$ to $437 \mathrm{~nm}$ in synthesis of Ag-Au NPs, as well as colour appeared, indicates a lower percentage of gold outside compared to silver, may be attributed to the Au core and Ag shell [28]. Alloy formation is evidenced by the appearance of a single peak depending strongly on composition. The Plasmon band is blue-shifted with increasing amount of silver at surface. The absorbance maxima were found to be at $440 \mathrm{~nm}$ region which indicates that the silver NPs formed the outer shell with gold as core.

From fluorescence spectroscopy it was found that $\mathrm{Au}$ 45.5nm, Ag 50nm and bimetallic Ag-Au 52.9nm NPs have the peak intensity maximum, which is more desirable as a fluorescent agent compared to other size nanoparticles of respective group. Lower wavelength in UV region corresponds to higher frequency and hence, higher Force Constant (molecules are executing simple harmonic motion (SHM) and associated with this we have a force constant) which is essentially means higher capacity to absorb incident radiation. Potential energy diagram of energy can be visualized for such process as in Figure 6. It essentially indicates that nanoparticles of gold, silver and silver-gold (bimetallic) have transition from higher energy to lower energy state in the excited region without emission of radiation and then there is emission of radiation when they make transition back to ground state with emission of radiation less compared to absorption frequency.

A typical energy spectrum of silver-gold nanoparticle 
sample with particle size $52.9 \mathrm{~nm}$ is as shown in figure 8 . Similar spectra which differed only in terms of their counts/channel were obtained for all other samples of interest. A suitable Lorentzian was fit to the photopeaks in each sample spectrum and the areas under the two photopeaks within a common region of interest were taken to be the intensity I. By using these intensities the mass attenuation coefficient $\mu / \rho$ was calculated from the well-known Beer's law, using the equation

$$
\mu / \rho=\ln \left(\mathrm{I} / \mathrm{I}_{0}\right) / \rho \mathrm{t}
$$

This was done for all samples of present interest (nanoparticles - colloidal solutions) for $1173 \mathrm{keV}$ and 1332 $\mathrm{keV}$ respectively.

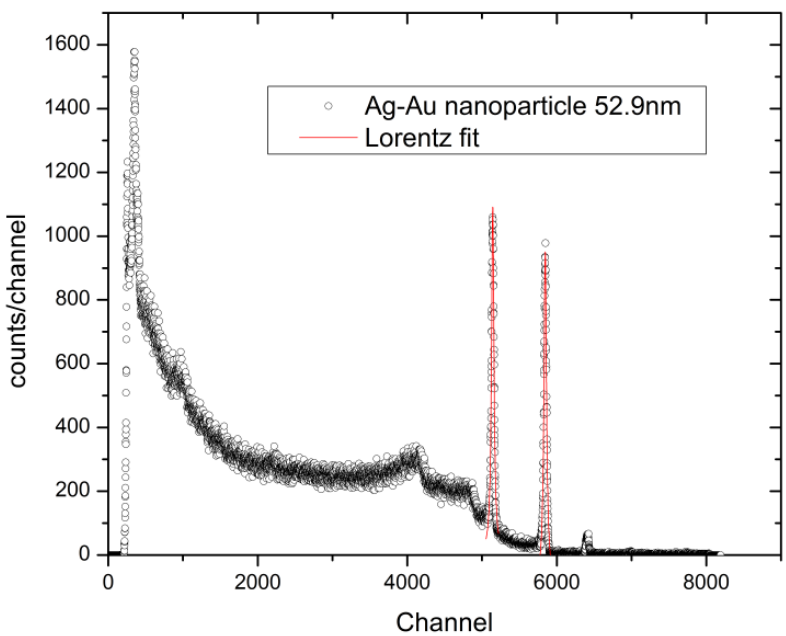

Figure 8. A typical energy spectrum of silver-gold bimetallic NP of size $52.9 \mathrm{~nm}$.

The main source of error in the transmission experiment was due to counting statistics. This error was less than $0.3 \%$ as the area under the peak was $10^{4}-10^{5}$ counts. The sample size was so chosen that the error due to multiple scattering was negligible.

There were several other possible sources of error in the present method. These were due to

a) Small-angle scattering contributions: In this experimental setup, a distance of $15 \mathrm{~cm}$ was maintained between the source and the detector. According to the theoretical estimates, the contribution of coherent as well as incoherent scattering at such small angle to the measured cross section at the energy of interest is negligibly small.

b) Photon build-up and pulse pile up effects: The photon dose buildup effects and pulse pile up effects were kept to a minimum by choosing an optimal count rate and counting time. The photon dose buildup is a function of the sample thickness, its atomic number, and the incident energy. It is also a consequence of multiple scattering occurring inside the sample. Since the multiple scattering effects are corrected, and an optimal count rate and counting time as well as a detector of good resolution were employed, it is expected that the effect of photon dose build up and pulse pileup was a minimum in the present study.

c) Dead time of the counting instrument: There was built-in provision for dead-time correction in the multichannel analyzer.

Thus the overall error on the measured mass attenuation coefficient was below $4 \%-5 \%$.

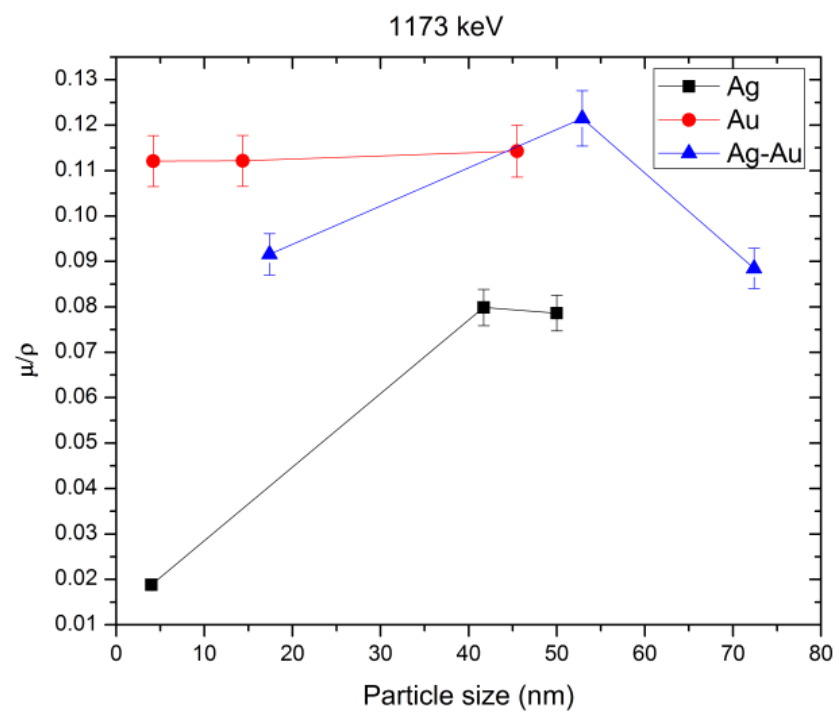

Figure 9(a). Variation of the mass attenuation coefficient of silver, gold and silver-gold (bimetallic) nanoparticles with different particle size at $1173 \mathrm{keV}$

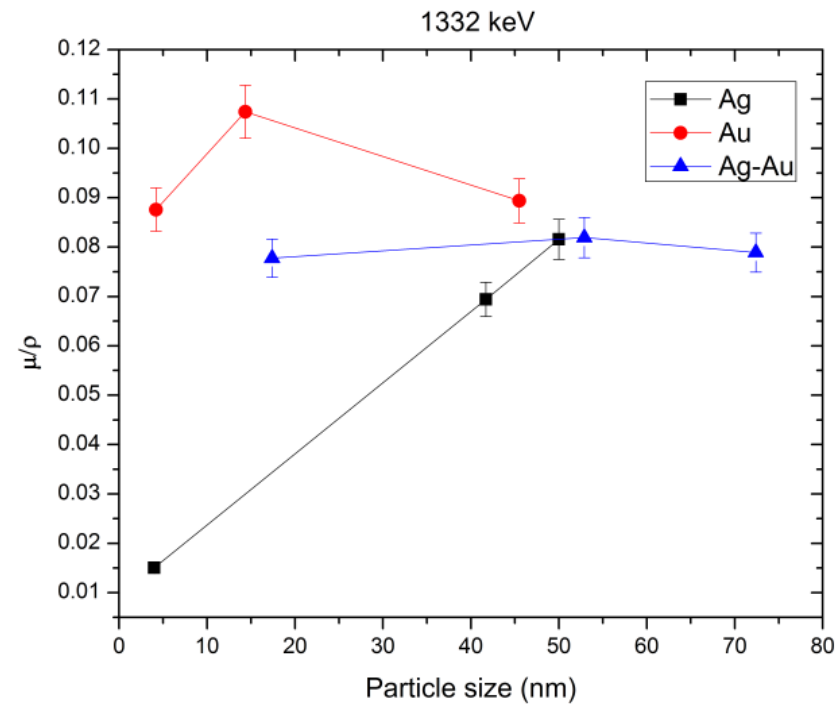

Figure 9(b). Variation of the mass attenuation coefficient of silver, gold and silver-gold (bimetallic) nanoparticles with different particle size at 1332 $\mathrm{keV}$.

Figure 9 (a) and 9 (b) indicate that

1) The $\mu / \rho$ value for Ag-Au NPs records a maximum at a particle size of around $50 \mathrm{~nm}$.

2) The Au NPs show almost a constant value of 0.11 and $0.08 \mathrm{~cm}^{2} / \mathrm{g}$ respectively for all particle sizes at 1173 and $1332 \mathrm{keV}$ 
3) At $1173 \mathrm{keV}$, the $\mu / \rho$ of Ag-Au NPs exhibits a maximum at a particle size of $50 \mathrm{~nm}$

4) At $1332 \mathrm{keV}$ the $\mu / \rho$ of Au NPs exhibits a maximum at $15 \mathrm{~nm}$.

Radiosensitizing mechanism of Ag NPs according to $\mathrm{Su}$ and coworkers is due to release of $\mathrm{Ag}+$ cation from the $\mathrm{Ag}$ nanostructures inside cell. $\mathrm{Ag}+$ cation has the ability to capture electron and thus functions as an oxidative agent, which could further reduce the ATP content of the cell and increase production of ROS. ROS formation when radiation interacts with gold NPs may be one of the mechanisms that mediate gold NP radiosensitization [29].

\section{Conclusions}

This is the first invitro study shows radio sensitisation capacity of silver, gold and silver-gold (bimetallic) nanoparticles as per the absorption studies. All the three types of nanoparticles were prepared using trisodium citrate as reducing agent via Chemical reduction and Hydrothermal synthesis resulting in fabrication of spherical type of nanoparticles in colloidal solution ranging from $4 \mathrm{~nm}$ to $70 \mathrm{~nm}$ as desired.

According to DLS data size of all nanoparticles was determined and also nanoparticles had negative charge on surface at around $-200 \mathrm{mV}$ suggestive of a stable colloidal solution of nanoparticles.

From UV-Visible spectroscopy we can infer the presence of silver, gold and bimetallic silver-gold NPs with their maximum absorption peaks at $400-450 \mathrm{~nm}, 525 \mathrm{~nm}$ and $400-450 \mathrm{~nm}$ respectively. The bimetallic silver-gold NPs maximum peak at $400-450 \mathrm{~nm}$ suggests that this consists of gold core with silver shell.

Fluorescence emission spectra for all 3 varieties of nanoparticles showed a peak at $450 \mathrm{~nm}$ which suggested that these were good fluorescent agents as well as bio-labelling materials in cancer cells. Particularly NPs of gold, silver and silver-gold around $40-50 \mathrm{~nm}$ showed higher intensity of emission. Hence, $50 \mathrm{~nm}$ particles are desirable as fluorescent agent.

From the gamma ray transmission experiment we observe that silver nanoparticles have the lowest mass attenuation coefficient, which is a measure of absorption. Gold nanopaticles had relatively uniform and higher mass attenuation coefficient for particle size up to $50 \mathrm{~nm}$. The maximum mass absorption coefficient was observed for particle size in the range $40-50 \mathrm{~nm}$ for all the three types of samples. Silver-gold had the maximum absorption coefficient corresponding to $52.9 \mathrm{~nm}$ at $1173 \mathrm{keV}$. Ag-Au nanoparticles were more desirable due to size and having enhanced gamma ray absorption capacity. Among the 3 types of NPs silver-gold NPs showed an increased radio sensitisation effect which is due to alloy of high $\mathrm{Z}$ elements attributing to increase in the electron cloud and also by synergistic combination of $\mathrm{Ag}$ and $\mathrm{Au}$ NPs radio sensitization mechanism.

On the whole, based on the present study it is felt that $\mathrm{Ag}$-Au nanoparticles and Au nanoparticles may prove to be versatile radiosensitizing agent for treating cancer tissues with relatively less radiation dosage up to 50 times. It is noteworthy that the non-toxicity and biocompatibility of these NPs has already been proven by studies reported earlier.

\section{Acknowledgements}

The authors would like to thank Institution of Excellence (IOE), University with Potential for Excellence (UPE), and DoS in Physics, University of Mysore, Manasagangotri, Mysuru for providing requisite facilities. One of the authors (BMS) would like to thank Department of Science and Technology, Government of India, New Delhi for providing DST-INSPIRE Fellowship during the course of present investigation.

\section{REFERENCES}

[1] Stewart, Bernard W., and Paul Kleihues, eds. World cancer report. Vol. 57. Lyon: IARC press, 2003.

[2] Hall, Eric J., and Amato J. Giaccia. Radiobiology for the Radiologist. Lippincott Williams \& Wilkins, 2006.

[3] Begg, Adrian C., Fiona A. Stewart, and Conchita Vens. "Strategies to improve radiotherapy with targeted drugs." Nature Reviews Cancer 11, no. 4 (2011): 239-253.

[4] M. Herold, IJ Das, CC Stobbe, RV Iyer, JD Chapman, D. "Gold microspheres: a selective technique for producing biologically effective dose enhancement." International journal of radiation biology 76, no. 10 (2000): 1357-1364.

[5] Park, Yeon-Su, Luis M. Liz-Marzán, Atsuo Kasuya, Yoshio Kobayashi, Daisuke Nagao, Mikio Konno, Sergiy Mamykin, Andriy Dmytruk, Motohiro Takeda, and Noriaki Ohuchi. "X-ray absorption of gold nanoparticles with thin silica shell." Journal of nanoscience and nanotechnology 6, no. 11 (2006): 3503-3506.

[6] Carter, Joshua D., Neal N. Cheng, Yongquan Qu, George D. Suarez, and Ting Guo. "Nanoscale energy deposition by X-ray absorbing nanostructures."The Journal of Physical Chemistry B 111, no. 40 (2007): 11622-11625.

[7] Kwatra, Deep, Anand Venugopal, and Shrikant Anant. "Nanoparticles in radiation therapy: a summary of various approaches to enhance radiosensitization in cancer." Translational Cancer research 2, no. 4 (2013): 330-342.

[8] Retif, Paul, Sophie Pinel, Magali Toussaint, Céline Frochot, Rima Chouikrat, Thierry Bastogne, and Muriel Barberi-Heyob. "Nanoparticles for radiation therapy enhancement: the key parameters." Theranostics 5, no. 9 (2015): 1030 .

[9] Hainfeld, James F., F. Avraham Dilmanian, Daniel N. Slatkin, 
and Henry M. Smilowitz. "Radiotherapy enhancement with gold nanoparticles." Journal of Pharmacy and Pharmacology 60, no. 8 (2008): 977-985.

[10] Townley, Helen E., Jeewon Kim, and Peter J. Dobson. "In vivo demonstration of enhanced radiotherapy using rare earth doped titania nanoparticles." Nanoscale 4, no. 16 (2012): 5043-5050.

[11] Mirjolet, C., A. L. Papa, G. Créhange, O. Raguin, C. Seignez, C. Paul, G. Truc, P. Maingon, and N. Millot. "The radiosensitization effect of titanate nanotubes as a new tool in radiation therapy for glioblastoma: a proof-of-concept." Radiotherapy and Oncology 108, no. 1 (2013): 136-142.

[12] Takahashi, Junko, and Masaki Misawa. "Analysis of potential radiosensitizing materials for $\mathrm{x}$-ray-induced photodynamic therapy."NanoBiotechnology 3, no. 2 (2007): 116-126.

[13] Yang, Wensha, Paul W. Read, Jun Mi, Joseph M. Baisden, Kelli A. Reardon, James M. Larner, Brian P. Helmke, and Ke Sheng. "Semiconductor nanoparticles as energy mediators for photosensitizer-enhanced radiotherapy." International Journal of Radiation Oncology* Biology* Physics72, no. 3 (2008): 633-635.

[14] Liu, Peidang, Zhihai Huang, Zhongwen Chen, Ruizhi Xu, Hao $\mathrm{Wu}$, Fengchao Zang, Cailian Wang, and Ning Gu. "Silver nanoparticles: a novel radiation sensitizer for glioma?." Nanoscale 5, no. 23 (2013): 11829-11836.

[15] Swanner, Jessica, Jade Mims, David L. Carroll, Steven A. Akman, Cristina M. Furdui, Suzy V. Torti, and Ravi N. Singh. "Differential cytotoxic and radiosensitizing effects of silver nanoparticles on triple-negative breast cancer and non-triple-negative breast cells." International journal of nanomedicine 10 (2015): 3937.

[16] Babaei, Mohammad, and Maryam Ganjalikhani. "The potential effectiveness of nanoparticles as radio sensitizers for radiotherapy." Bioimpacts 4, no. 1 (2014): 15.

[17] Chithrani, Devika B., Salomeh Jelveh, Farid Jalali, Monique van Prooijen, Christine Allen, Robert G. Bristow, Richard P. Hill, and David A. Jaffray. "Gold nanoparticles as radiation sensitizers in cancer therapy." Radiation research 173, no. 6 (2010): 719-728.

[18] Chithrani, B. Devika, Arezou A. Ghazani, and Warren CW Chan. "Determining the size and shape dependence of gold nanoparticle uptake into mammalian cells." Nano letters 6 , no. 4 (2006): 662-668.

[19] Turkevich, John, Peter Cooper Stevenson, and James Hillier. "A study of the nucleation and growth processes in the synthesis of colloidal gold."Discussions of the Faraday
Society 11 (1951): 55-75.

[20] Chattopadhyay, Niladri, Zhongli Cai, Jean-Philippe Pignol, Brian Keller, Eli Lechtman, Reina Bendayan, and Raymond M. Reilly. "Design and characterization of HER-2-targeted gold nanoparticles for enhanced X-radiation treatment of locally advanced breast cancer." Molecular pharmaceutics 7, no. 6 (2010): 2194-2206.

[21] Ratyakshi, and R. P. Chauhan. "Colloidal synthesis of silver nano particles." Asian Journal of Chemistry 21, no. 10 (2009): 113-116.

[22] Apanasevich, V., V. Avramenko, P. Lukyanov, A. Lagureva, A. Polkovnikova, K. Lukyanenko, V. Kustov et al. "Enhance the Absorption of Gamma-ray Energy inside the Tumor Using Gold Nanoparticles and Iodine Particles." Cancer and Oncology Research 2, no. 2 (2014): 17-20.

[23] Vijayakumar, S. "In vitro stability studies on gold nanoparticles with different stabilizing agents." Int. J. Curr. Sci 11 (2014): 84-93.

[24] Islam, Nazar Ul, Raza Amin, Muhammad Shahid, and Muhammad Amin. "Gummy gold and silver nanoparticles of apricot (Prunus armeniaca) confer high stability and biological activity." Arabian Journal of Chemistry (2016).

[25] Liu, Wei, QunFang Zhou, JiYan Liu, JianJie Fu, SiJin Liu, and GuiBin Jiang. "Environmental and biological influences on the stability of silver nanoparticles." Chinese Science Bulletin 56, no. 19 (2011): 2009-2015.

[26] Liu, Li, Hu-Zhi Zheng, Zhu-Jun Zhang, Yu-Ming Huang, Su-Ming Chen, and Yu-Fei Hu. "Photoluminescence from water-soluble BSA-protected gold nanoparticles." Spectrochimica Acta Part A: Molecular and Biomolecular Spectroscopy 69, no. 3 (2008): 701-705.

[27] Umesh, T. K., C. Ranganathaiah, and B. Sanjeevaiah. "Incoherent-scattering cross sections of Co $60 \gamma$ rays in elements." Physical Review A 29, no. 1 (1984): 387.

[28] Shankar, S. Shiv, Akhilesh Rai, Absar Ahmad, and Murali Sastry. "Rapid synthesis of Au, Ag, and bimetallic Au coreAg shell nanoparticles using Neem (Azadirachta indica) leaf broth." Journal of colloid and interface science 275 , no. 2 (2004): 496-502.

[29] Su, Xiang-Yu, Pei-Dang Liu, Hao Wu, and Ning Gu. "Enhancement of radiosensitization by metal-based nanoparticles in cancer radiation therapy." Cancer biology \& medicine 11, no. 2 (2014): 86-91. 